\title{
The effects of epidural anaesthesia and analgesia on T lymphocytes differentiation markers and cytokines in patients after gastric cancer resection
}

\author{
Liping Wang ${ }^{1+}$, Si Liang ${ }^{2+}$, Hong Chen ${ }^{1}$, Yang $X u^{1}$ and Yu Wang ${ }^{1 *}$ (D)
}

\begin{abstract}
Background: Epidural use can prevent peri-operative neuro-endocrine stress responses, mitigate pain after surgery, and reduce opioid use, which all lead to immunosuppression.

Methods: Forty patients with gastric cancer were ultimately enrolled into the study. Patients who received general anaesthesia (GA group, $n=20$ ) or a combination of general anaesthesia and peri-operative epidural use (EGA group, $n=20$ ) were given intravenous analgesia or epidural analgesia, respectively. We collected visual analogue scale (VAS) scores, length of hospital stay, the time of the first passage of flatus and incidence of postoperative nausea and vomiting (PONV). We also collected data on the cluster of differentiation markers $(C D)^{3+}, C^{4+}, C D^{8+}, C D^{4+} / C^{8+}$, interleukin (IL)-4, IL-6, and interferon (IFN)- $\gamma$ the day before surgery as well as on postoperative days 1, 3, and 7 .

Results: VAS scores and PONV in the GA group were higher than in the EGA group on postoperative day 3. $\mathrm{CD}^{3+}, \mathrm{CD}^{4+}$, and $\mathrm{CD}^{4+} / \mathrm{CD}^{8+} \mathrm{T}$ cells declined on postoperative day 3 and nearly recovered to baseline seven days after surgery in both groups. $C D^{3+}$ T cells decreased more in the GA group than in the EGA group. IL-4, IL-6, and IFN- $\gamma$ increased on postoperative day 3 and nearly recovered to baseline seven days after surgery in both groups. IL-4 and IL-6 increased more in the GA group than in the EGA group. IFN- $\gamma$ increased more in the EGA group than in the GA group.
\end{abstract}

Conclusions: A combination of general anaesthesia and peri-operative epidural use can relieve postoperative pain and PONV. A combination of general anaesthesia and peri-operative epidural use decreases immunosuppression in gastric cancer resection.

Trial registration: The study procedures were approved by the Ethics Committee of The Harbin Medical University Cancer Hospital. This study was registered prospectively at http://www.chictr.org.cn/index.aspx on October 10, 2017 (Registered ChiCTR-INR-17012939).

Keywords: Epidural anaesthesia, General anaesthesia, Patient-controlled analgesia, Immune function, Cluster of differentiation, Cytokines

\footnotetext{
* Correspondence: littlepigdiudiu@163.com

†Liping Wang and Si Liang contributed equally to this work.

${ }^{1}$ Department of Anaesthesiology, Harbin Medical University Cancer Hospital,

No. 150 Haping Rd., Nangang District, Harbin 150081, China

Full list of author information is available at the end of the article
}

(c) The Author(s). 2019 Open Access This article is distributed under the terms of the Creative Commons Attribution 4.0 International License (http://creativecommons.org/licenses/by/4.0/), which permits unrestricted use, distribution, and reproduction in any medium, provided you give appropriate credit to the original author(s) and the source, provide a link to the Creative Commons license, and indicate if changes were made. The Creative Commons Public Domain Dedication waiver (http://creativecommons.org/publicdomain/zero/1.0/) applies to the data made available in this article, unless otherwise stated. 


\section{Background}

The stress response induced by surgery can activate the immune regulation mechanism during a systemic inflammatory reaction [1-4]. There are many important contributors to the tumor microenvironment, such as cytokines, chemokines, inflammatory mediators, which exists in many stages of progression to metastasis [5-7]. Some clinical factors, such as general anaesthetics, postoperative pain, and opioid analgesia, have been recognized as immunosuppressive and have influenced the development of tumours [814]. In some studies, epidural anaesthesia (EA) was associated with improved overall survival in patients with gastric cancer; in other studies, EA did not improve overall survival [15-17]. EA may reduce cytokines and neuroendocrine stress immune stimulation, prevent nerve impulses, decrease excitability of the sympathetic adrenal medulla axis, reduce cortisol production, and improve the function of T lymphocytes [18, 19].

Among cytokines, interleukin (IL)-4, IL-6, and interferon (IFN) $\gamma$ play prominent roles in chronic inflammation, autoimmunity, infectious diseases and cancer, where they often act as diagnostic or prognostic indicators of disease activity and response to therapy [20, 21]. Therefore, we designed this study to explore the interaction between epidural use and the aforementioned cytokines in patients with gastric cancer.

\section{Methods}

\section{Patient identification and exclusion}

This study was a single-centre, randomized, observerblinded study. The study procedures were approved by the Ethics Committee of The Harbin Medical University Cancer Hospital. This study was registered prospectively at http://www.chictr.org.cn/index.aspx on October 10, 2017 (Registered ChiCTR-INR-17012939). After the written consent was obtained from study participants, 50 American Society of Anesthesiologists (ASA) I-II patients aged 20-80 yr. who underwent radical resection of gastric cancer in our hospital were enrolled in this study between November 12, 2017, and December 15, 2017. Exclusion criteria were: (1) emergency operations, (2) laparoscopic procedures,(3) neoadjuvant treatment,(4) abnormally white blood cell count, (5) peri-operative transfusion, (6) severe heart, lung, liver, kidney, or endocrine diseases, After confirming understanding of the recruiter's description of the trial, all the patients signed informed consent forms. Anaesthesia and analgesia protocols were standardized as follows. Patients were randomly assigned to the general anaesthesia (GA) group or epidural anaesthesia (EGA) group by computergenerated codes on the beginning of the study.

\section{Sample size calculation and masking method}

The clear primary outcome of this study was inflammatory response, which was evaluated via the concentration of IL-6. Previously published studies on IL-6 suggested that its standard deviation (SD) in vivo is in the order of $7.6 \mathrm{pg} / \mathrm{ml}$. Twenty patients were calculated based on detecting a reduction of $6.8 \mathrm{pg} / \mathrm{ml}$ deviation on $\alpha$-value 0.05 and a power of 0.8 . To compensate for potential dropouts, we enrolled Twenty-five patients.

The patients were randomly divided into two groups by computer-generated codes on the time of the study onset. Physicians who completed postoperative assessment and biological detection were blinded to the group assignments throughout the study period until follow-up was completed for final analysis.

\section{Anaesthesia technique and grouping method}

On arrival to the operating room, patients were monitored via electrocardiogram and blood pressure as well as pulse oximetry. Patients randomly assigned to the GA group underwent induction of balanced GA with $0.05 \mathrm{mg} / \mathrm{kg}$ midazolam (Enhua Pharmaceutical Co., Jiangsu, China), $0.2 \mu \mathrm{g} /$ kg sufentanil (Renfu Pharmaceutical Co., Beijing, China), $1-1.5 \mathrm{mg} / \mathrm{kg}$ propofol (AstraZeneca Pharmaceutical Co., Shanghai, China), and $0.15 \mathrm{mg} / \mathrm{kg}$ cisatracurium (Hengrui Medicine Co., Jiangsu, China). Anaesthesia was maintained with propofol when the bispectral index (BIS) was 40-60, and intraoperative analgesia consisted of remifentanil (Enhua Pharmaceutical Co., Jiangsu, China). Oesophageal temperature was monitored and maintained above $36^{\circ} \mathrm{C}$. Patient-controlled intravenous analgesia (PCIA) with sufentanil $(0.5 \mu \mathrm{g} / \mathrm{ml})$ was available for $72-120 \mathrm{~h}$. The PCIA protocol of the sufentanil group (S group) consisted of $0.5 \mu \mathrm{g} / \mathrm{ml}$ sufentanil (total $300 \mathrm{ml}$ ) with a background infusion rate of $4 \mathrm{ml} \mathrm{h}^{-1}$, a bolus dose of $3 \mathrm{ml}$, and a lockout time of $15 \mathrm{~min}$. Patients in the EGA group were given $\mathrm{T}_{8-}$ 10 epidural anaesthesia before general anaesthesia. An infusion of $0.5 \%$ ropivacaine (AstraZeneca Pharmaceutical Co., Shanghai, China) was administered during surgery, and the loading dose ( $0.5 \%$ ropivacaine, $5-7 \mathrm{ml})$ depended on the height and weight of the patient. GA was induced with $0.05 \mathrm{mg} / \mathrm{kg}$ midazolam, $0.2 \mu \mathrm{g} / \mathrm{kg}$ sufentanil, $1-1.5 \mathrm{mg} / \mathrm{kg}$ propofol, and $0.15 \mathrm{mg} / \mathrm{kg}$ cisatracurium, and anaesthesia was maintained with propofol when the bispectral index (BIS) was 40-60. Patient-controlled epidural analgesia (PCEA) with a combination of $0.2 \%$ ropivacaine and $0.5 \mu \mathrm{g} / \mathrm{ml}$ sufentanil was available for $72-120 \mathrm{~h}$. Acute rescue analgesic medications could be used when the VAS score was more than 4 and a bolus of $100 \mathrm{mg}$ tramadol, administered via intravenous injection, was required more than 3 times.

\section{Indicator and data}

A physician who was blinded to the group assignment assessed postoperative pain intensity using the visual analogue scale (VAS) on postoperative days 1,2 , and 3 . The demographic data, cancer stage, degree of differentiation, 
duration of the operation, length of hospital stay, time of the first passage of flatus and incidence of postoperative nausea and vomiting (PONV) were recorded. A physician who was blinded to the group assignment collected data on cluster of differentiation markers $(\mathrm{CD})^{3+}, \mathrm{CD}^{4+}, \mathrm{CD}^{8+}$, and $\mathrm{CD}^{4+} / \mathrm{CD}^{8+}$, Interleukin (IL)-4, IL-6, and Interferon (IFN)- $\gamma$ through peripheral blood $(10 \mathrm{ml})$ on the day before surgery, day (d) 0 , and on postoperative days 1,3 , and 7. $\mathrm{CD}^{3+}, \mathrm{CD}^{4+}, \mathrm{CD}^{8+}$ were measured by flow cytometric analysis. The plasma level of IL-4, IL-6, and Interferon IFN- $\gamma$ were measured by enzyme-linked immunosorbent assay (ELISA). All samples were measured using three independent experiments.

\section{Statistical approach}

Statistical analysis was performed using SPSS version 22.0 for Windows (IBM Corp., USA). Normally distributed data were expressed as the means \pm SDs. Categorical variables were described using frequencies and were analysed using the $\chi^{2}$ test. Fisher's exact test was used for small sample sizes (expected frequencies $<5$ ). We checked for normality of the data with the Shapiro Wilk test and used a one-way ANOVA between the two groups. The results with $P<0.05$ were considered statistically significant.

\section{Results}

\section{Patient characteristics}

Between November 12, 2017, and December 15, 2017, fifty patients were screened for this study, and forty patients were ultimately included in this study. Five patients with metastases or peri-operative transfusions were excluded. Five patients had their analgesic regimen modified because of hypotension and severe nausea (Fig. 1). The two groups were similar with respect to age, height, weight, gender, ASA grade, cancer stage and degree of differentiation, duration of surgery, surgical procedure and surgical manner between the two groups (Table 1).

\section{Association between epidural use and postoperative variables}

The VAS scores in the GA group were higher than in the EGA group on postoperative day 3 , and the incidence of PONV in the EGA group was lower $(P<0.05$, Table 2$)$. There were no differences in days of analgesia, the time of the first passage of flatus, and length of hospital stay. $\mathrm{CD}^{3+}$, $\mathrm{CD}^{4+}$, and $\mathrm{CD}^{4+} / \mathrm{CD}^{8+} \mathrm{T}$ cells declined on postoperative day $3(P<0.05)$ and nearly recovered to baseline seven days after surgery in both groups. $\mathrm{CD}^{3+} \mathrm{T}$ cells decreased more in the GA group than in the EGA group $(P<0.05$, Table 3$)$. IL-4, IL-6, and IFN- $\gamma$ increased on postoperative day 3 $(P<0.05$; Figs. 2,3 , and 4$)$ and nearly recovered to baseline seven days after surgery in both groups. IL-4 and IL-6 increased more in the GA group than in the EGA group $(P<0.05$, Figs. 2 and 3). IFN- $\gamma$ increased more in the EGA group than in the GA group $(P<0.05$, Fig. 4$)$.

\section{Discussion}

In our study, we found a beneficial effect of epidural use. The VAS scores in the GA group were higher than those in the EGA group on postoperative day three. The incidence

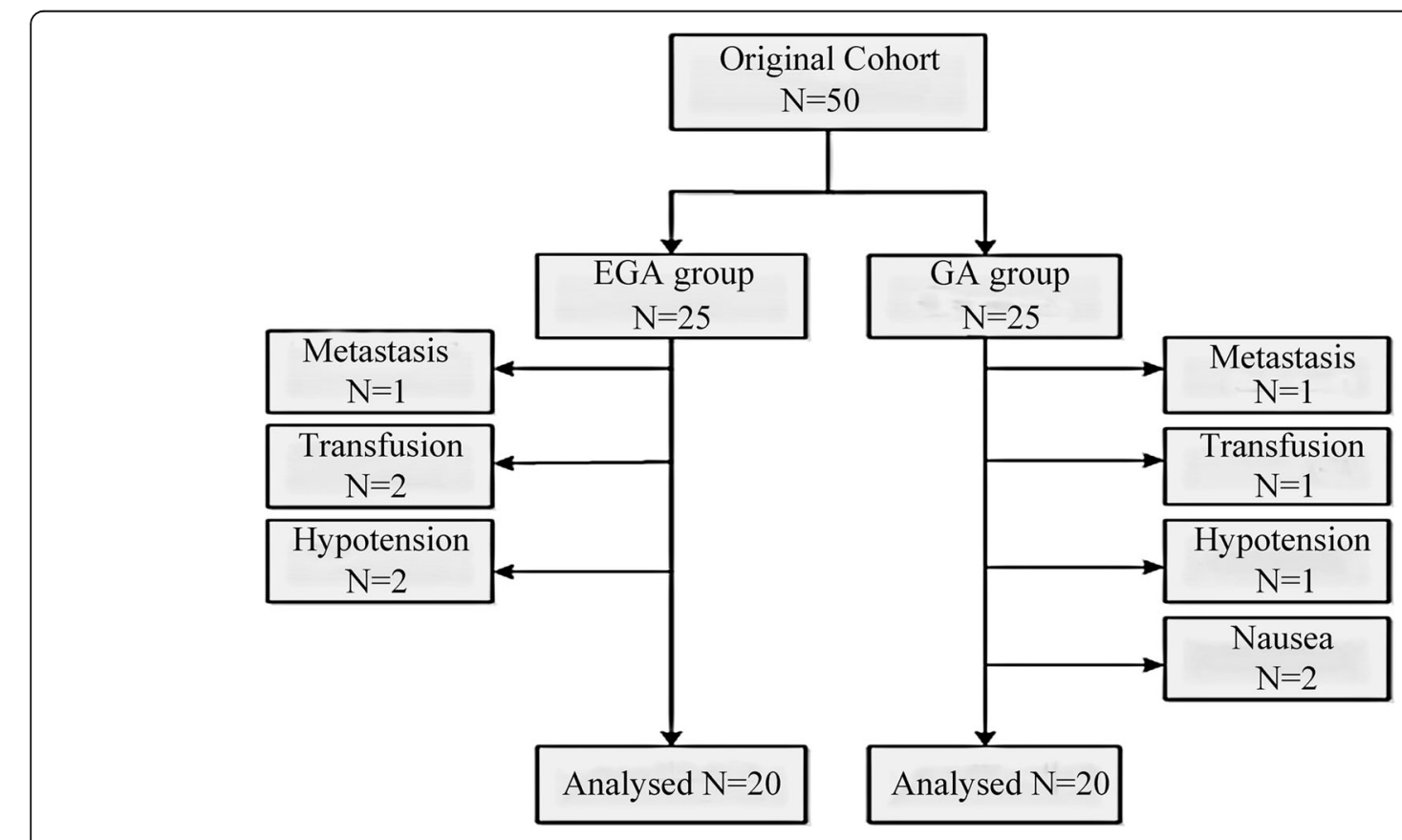

Fig. 1 Patient identification and exclusion 
Table 1 Baseline and surgical characteristics of general anesthesia group and epidural combined general anesthesia group

\begin{tabular}{|c|c|c|c|}
\hline Characteristics & GA group $(n=20)$ & EGA group $(n=20)$ & $P$ value \\
\hline Age (year) & $59.3 \pm 6.8$ & $59.7 \pm 8.5$ & 0.870 \\
\hline Height (cm) & $164.0 \pm 6.1$ & $164.5 \pm 8.7$ & 0.832 \\
\hline Weight (kg) & $66.5 \pm 8.4$ & $64.3 \pm 7.7$ & 0.394 \\
\hline Gender (male) & $11(55 \%)$ & $10(50 \%)$ & 0.752 \\
\hline \multicolumn{4}{|l|}{ ASA grade } \\
\hline । & $2(10 \%)$ & $2(10 \%)$ & \multirow[t]{3}{*}{1.000} \\
\hline$\|$ & $16(80 \%)$ & $17(85 \%)$ & \\
\hline III & $2(10 \%)$ & $1(5 \%)$ & \\
\hline \multicolumn{4}{|l|}{ Cancer stage } \\
\hline । & $3(15 \%)$ & $4(20 \%)$ & \multirow[t]{4}{*}{0.925} \\
\hline$\|$ & $2(10 \%)$ & $2(10 \%)$ & \\
\hline III & $12(60 \%)$ & $10(50 \%)$ & \\
\hline Cancer stagelV & $3(15 \%)$ & $4(20 \%)$ & \\
\hline \multicolumn{4}{|l|}{ Degree of differentiation } \\
\hline 1 & $7(35 \%)$ & $5(25 \%)$ & \multirow[t]{4}{*}{0.915} \\
\hline 2 & $10(50 \%)$ & $11(55 \%)$ & \\
\hline 3 & $2(10 \%)$ & $2(10 \%)$ & \\
\hline 4 & $1(5 \%)$ & $2(10 \%)$ & \\
\hline Duration of surgery (h) & $2.25(2.00,3.75)$ & $2.25(2.00,3.50)$ & 0.577 \\
\hline \multicolumn{4}{|l|}{ Surgical procedure } \\
\hline open & $20(100 \%)$ & $20(100 \%)$ & \multirow[t]{2}{*}{1.000} \\
\hline minimal invasive & $0(0 \%)$ & $0(0 \%)$ & \\
\hline \multicolumn{4}{|l|}{ Surgical manner } \\
\hline total & $20(100 \%)$ & $20(100 \%)$ & \multirow[t]{2}{*}{1.000} \\
\hline partial & $0(0 \%)$ & $0(0 \%)$ & \\
\hline
\end{tabular}

$\mathrm{GA}=$ general anesthesia group

$E G A=$ epidural anesthesia combined with general anesthesia group

ASA = American Society of Anesthesiologists

Cancer stages: I grade-T1, N0, MO/T2, NO, MO/T1, N1, MO; II grade-T3, N0, MO/

$\mathrm{T} 4 \mathrm{a}, \mathrm{N} 1, \mathrm{MO} / \mathrm{T} 3, \mathrm{~N} 1, \mathrm{MO} / \mathrm{T} 2, \mathrm{~N} 2, \mathrm{MO} / \mathrm{T} 1, \mathrm{~N} 3, \mathrm{M0}$; III grade-T2, N3, MO/T3, N2, MO/

$\mathrm{T} 3, \mathrm{~N} 3, \mathrm{MO} / \mathrm{T} 4 \mathrm{a}, \mathrm{N} 2, \mathrm{MO} / \mathrm{T} 4 \mathrm{a}, \mathrm{N} 3, \mathrm{MO}$ / any $\mathrm{T} 4 \mathrm{~b}$, any $\mathrm{N}, \mathrm{MO}$; IV grade, any $\mathrm{T}$, any

$\mathrm{N}, \mathrm{M} 1$

Degrees of differentiation: Degree1, poorly differentiated; Degree2, moderately differentiated; Degree3, well differentiated; Degree 4,

other/unknown differentiated

of PONV was higher in the GA group. It has been proven that epidural anaesthesia can provide better analgesia after gastric cancer surgery, which was consistent with our study [22]. Epidural administration of anaesthesia and analgesia is considered a technique with risk of complications, such as neuraxial haematoma, hypotension, pruritus; the subjective experience of anaesthetists often leads to the failure of epidural anaesthesia and analgesia [23, 24]. In our study, there were two patients in the EGA group and one patient in the GA group who could not use EA because of hypotension.

Many studies have reported that opioids impair the peri-operative immune system and increase vascular
Table 2 The VAS scores of patients in the postoperative days 1 , 2, 3 between general anesthesia group and epidural combined general anesthesia group

\begin{tabular}{llll}
\hline Characteristics & $\begin{array}{l}\text { GA group } \\
(n=20)\end{array}$ & $\begin{array}{l}\text { EGA group } \\
(n=20)\end{array}$ & $P$ value \\
\hline VAS scores & & $2(1,4)$ & $0.004^{*}$ \\
POD1 & $3(2,5)$ & $1(0,3)$ & $0.003^{*}$ \\
POD2 & $2(1,4)$ & $0(0,2)$ & $0.003^{*}$ \\
POD3 & $1(0,3)$ & $3(3,5)$ & 0.527 \\
Days of analgesia & $3(3,5)$ & $3(2,4)$ & 0.764 \\
Days of flatus time & $3(3,4)$ & $1(5 \%)$ & $0.020^{*}$ \\
Nausea and vomiting $(\%)$ & $8(40 \%)$ & $11(9,12)$ & 0.795 \\
\hline Length of stay & $11(9,12)$ & & \\
\hline
\end{tabular}

VAS=Visual analogue scale (VAS) scores

POD = Postoperative day

*: Compare between two groups, $P<0.05$

permeability, and the use of epidural anaesthesia may prevent these peri-operative immunosuppressive changes during major surgery because it can decrease neuroendocrine stress responses [18, 25-28]. Immune surveillance is the primary indicator for stopping the metastasis of tumours, and immunosuppression may destroy the defensive barrier [29]. Clinical events that may lead to immunosuppressive changes facilitated by surgery include injury, pain, and use of anaesthetic medications [30-32]. $\mathrm{CD}^{3+} \mathrm{T}$ cells, $\mathrm{CD}^{4+} \mathrm{T}$ cells, and $\mathrm{CD}^{8+} \mathrm{T}$ cells are the main cells which take part in antitumour immunity [33]. The ratio of $\mathrm{CD}^{4+} / \mathrm{CD}^{8+}$ cells decreases as the serum cortisol levels increase [34, 35]. In our study, $\mathrm{CD}^{3+}, \mathrm{CD}^{4+}$, and $\mathrm{CD}^{4+} / \mathrm{CD}^{8+} \mathrm{T}$ cells were inhibited and had a negative trend. All patients' $\mathrm{CD}^{3+}$ and $\mathrm{CD}^{4+} \mathrm{T}$ cells decreased to different degrees on the first postoperative day, but in the GA group, patients' $\mathrm{CD}^{3+} \mathrm{T}$ cells significantly decreased and recovered to preoperative levels until the seventh postoperative day. The change in $\mathrm{CD}^{8+} \mathrm{T}$ cells was not statistically significant. These results are consistent with some prior studies $[36,37]$,they described a lymphocyte

Table 3 Comparison of T lymphocyte subsets of patients in general anesthesia group and epidural combined general anesthesia group

\begin{tabular}{llllll}
\hline Characteristics & Group & $\mathrm{d} 0$ & $\mathrm{~d} 1$ & $\mathrm{~d} 3$ & $\mathrm{~d} 7$ \\
\hline $\mathrm{CD}^{+}(\%)$ & GA & $54.3 \pm 3.5$ & $42.5 \pm 2.3 \#$ & $44.6 \pm 3.2 \#$ & $51.8 \pm 6.7$ \\
& EGA & $55.6 \pm 4.1$ & $46.1 \pm 2.9 \#^{*}$ & $48.1 \pm 2.2 \#^{*}$ & $51.2 \pm 6.9$ \\
$\mathrm{CD}^{+}(\%)$ & GA & $32.4 \pm 4.3$ & $21.5 \pm 3.4 \#$ & $23.2 \pm 1.6 \#$ & $31.7 \pm 2.8$ \\
& EGA & $34.5 \pm 3.5$ & $23.4 \pm 3.5 \#$ & $24.5 \pm 2.1 \#$ & $33.0 \pm 2.0$ \\
$\mathrm{CD}^{+}(\%)$ & GA & $21.1 \pm 1.8$ & $20.7 \pm 1.8$ & $21.0 \pm 1.9$ & $20.9 \pm 1.3$ \\
& EGA & $21.5 \pm 1.2$ & $21.2 \pm 1.1$ & $22.9 \pm 2.0$ & $21.3 \pm 1.5$ \\
$\mathrm{CD}^{+} / \mathrm{CD}^{+}$ & GA & $1.5 \pm 0.5$ & $1.0 \pm 0.2 \#$ & $1.0 \pm 0.1 \#$ & $1.5 \pm 0.2$ \\
& EGA & $1.6 \pm 0.5$ & $1.2 \pm 0.2 \#$ & $1.2 \pm 0.3 \#$ & $1.5 \pm 0.1$ \\
\hline
\end{tabular}

$\mathrm{CD}=$ Clusters of Differentiation

\#: Compare to d0 $P<0.05$, *:Compare between two groups, $P<0.05$ 


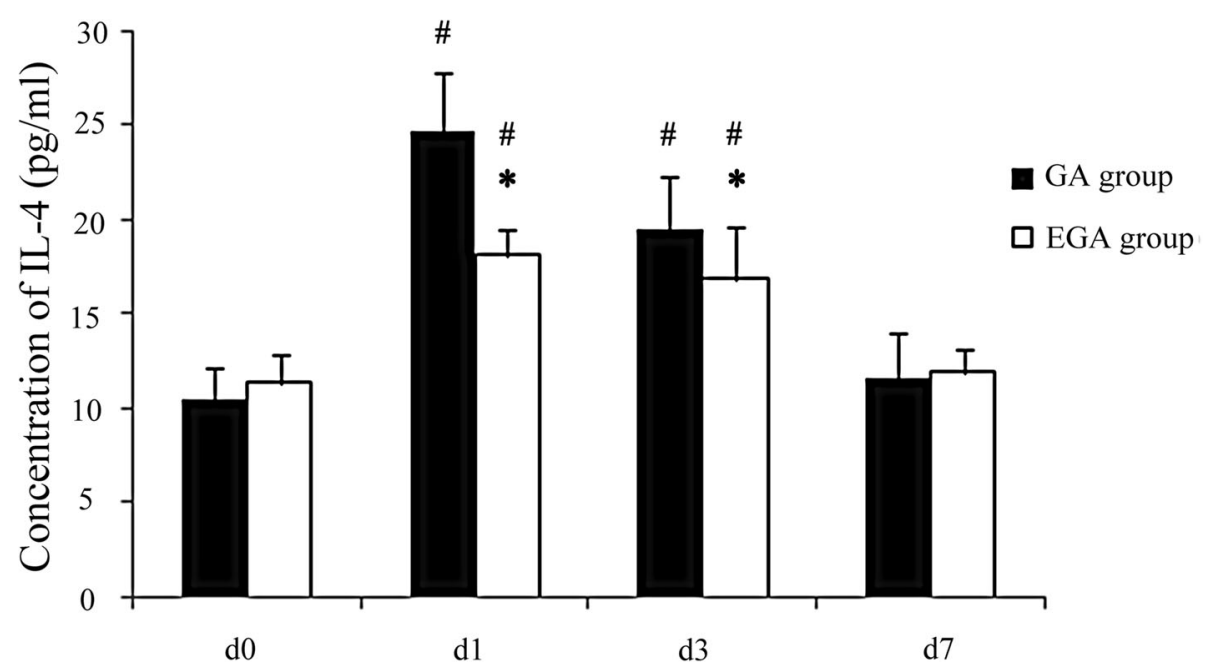

Fig. 2 Comparison of IL-4 between the general anaesthesia group and epidural combined with general anaesthesia group on day (d) 0 , the day before surgery, and on postoperative days 1, 3, and 7

depressing factor that was present in the serum of patients in the GA group but was absent in the serum of patients in the EGA group.

Many cytokines can modulate the immune system. Proinflammatory cytokines may favour tumour progression. Activated biological cascades lead to immunosuppression, which affects the immune response and decreases IL-4 and IFN- $\gamma[38,39]$. As a pro-inflammatory factor, IL-4 stimulates the proliferation of $B$ cells and participates in the differentiation of Th2 cells. The combination of the cytokine IL- 6 with prostaglandin 2 can reduce the production of the immune factor IL- 2 by Th1 cells and affect the activation of NK cells [40]. IL-6 has a major influence on the proliferation, survival and metastatic properties of cancerous cells, and studies using preclinical mouse models indicate that treatments targeting IL- 6 or its receptor display therapeutic efficacy as anticancer agents [20].In our study, the pro-inflammatory cytokines IL-4 and IL-6 increased more in the GA group than in the EGA group, which may indicate that immune function was less suppressed in the EGA group. IFN- $\gamma$ can kill tumour cells directly and transform Th0 cells into Th1 cells, which play a large role in the activation of NK cells and $\mathrm{T}$ cells. The level of IFN- $\gamma$ expression embodies the memory ability of this antitumour cytokine [41, 42]. In our study, IFN- $\gamma$ increased more in the EGA group than

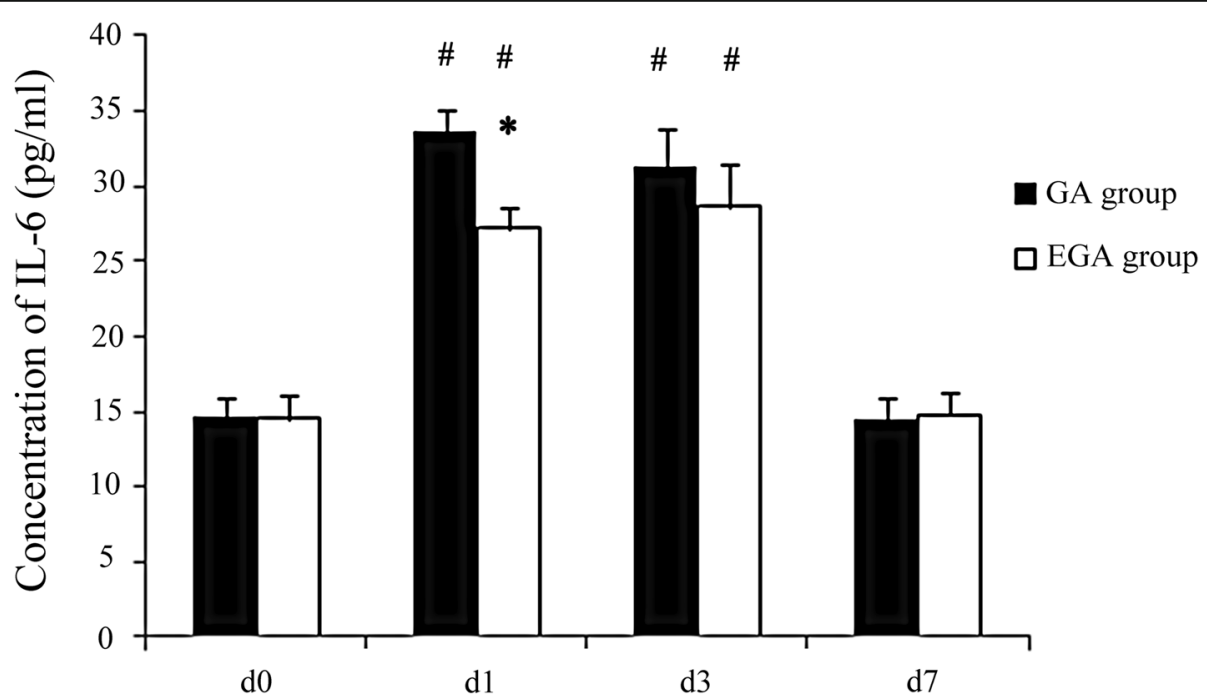

Fig. 3 Comparison of IL-6 between the general anaesthesia group and epidural combined with general anaesthesia group on day (d) 0 , the day before surgery, and on postoperative days 1,3 , and 7 


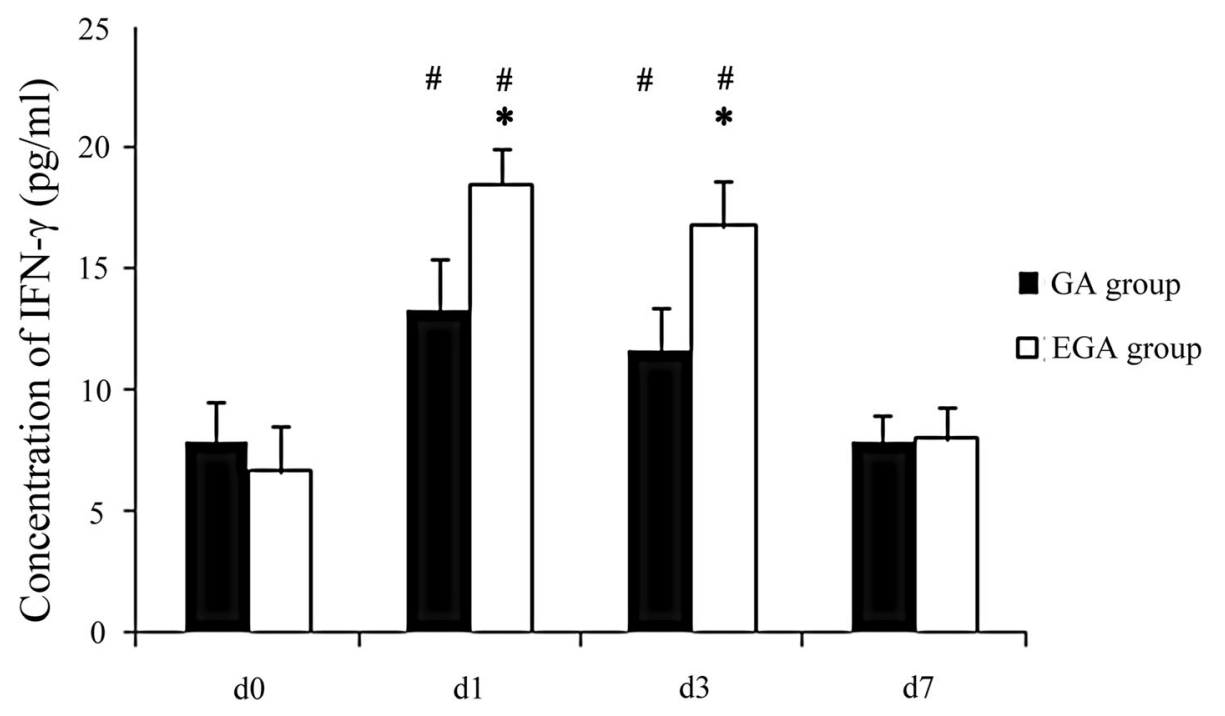

Fig. 4 Comparison of IFN- $\gamma$ between the general anaesthesia group and epidural combined with general anaesthesia group on day (d) 0 , the day before surgery, and postoperative days 1, 3, and 7

in the GA group, which may indicate that immune function was less suppressed in the EGA group. Therefore, in our study, EA was able to relieve postoperative pain and PONV, was able to decrease immunosuppression, and may have reduced inflammatory-associated metastasis in gastric cancer.

There were a few limitations in our study. First, we only measured some $\mathrm{T}$ cell subsets and some important immune factors. The immune system is a complex system. There are many immune cells, such as NK cells, and other immune factors, such as IL-2 and IL-12, which may be investigated in the future because these antitumourigenic cytokines were increased by EA. Second, these patients' long-term outcomes, such as long-term survival, recurrence rates and metastasis rates, could not be obtained at present. We will evaluate these results in 3 to 5 years.

\section{Conclusions}

A combination of general anaesthesia and peri-operative epidural use can relieve postoperative pain and PONV. A combination of general anaesthesia and peri-operative epidural use decreases immunosuppression in gastric cancer resection.

\section{Abbreviations}

(NK) cell: Natural killer cell; ASA: American Society of Anesthesiologists; BIS: Bispectral index; EGA: Epidural general anaesthesia; GA: General anaesthesia; IFN: Interferon; IL: Interleukin; PCEA: Patient-controlled epidural analgesia; PCIA: Patient-controlled intravenous analgesia;

PONV: Postoperative nausea and vomiting; VAS: Visual analogue scale

Acknowledgements

Not applicable.

\section{Authors' contributions}

Y.W. and L.W. contributed to the study conception and the designing and drafting of the manuscript. L.W., S.L., C.H. and Y.X. contributed to acquisition and interpretation of the data. H.C. and L.W. were responsible for the revision of important intellectual content and final approval of the version to be published. All authors read and approved the final manuscript.

\section{Funding}

This study was supported by the Education Office of Hei Longjiang (the Fundamental Research Funds for the Provincial Universities, Grant\#2017LCZX90) and the Postdoctoral Office of Heilongjiang Province (Hei Long Jiang Postdoctoral Foundation Grant\#LBH-Z17181).

\section{Availability of data and materialS}

All data generated or analysed during this study are included in this published article, and can be freely available to any scientists wishing to use. The data supporting our findings can be found in http://www.chictr.org.cn/ index.aspx (Registered ChiCTR-INR-17012939), but identifying patient data would not be shared. All the authors agreed to share their data.

Ethics approval and consent to participate

The study procedures were approved by the Ethics Committee of The Harbin Medical University Cancer Hospital. This study was registered prospectively at http://www.chictr.org.cn/index.aspx on October 10, 2017 (Registered ChiCTR-INR-17012939). The purpose of the study was explained to the family of patients under the study. The written consent was obtained from study participants. The patients were informed that the care to be given was not be compromised in any way and confidentiality was assured. Name and other identifying information were not used in the study.

Consent for publication

Not applicable.

Competing interests

The authors declare that they have no conflicts of interest.

\section{Author details}

'Department of Anaesthesiology, Harbin Medical University Cancer Hospital, No. 150 Haping Rd., Nangang District, Harbin 150081, China. ${ }^{2}$ Department of Anaesthesiology, Affiliated Hospital of HeBei University, Baoding, China. 
Received: 19 November 2018 Accepted: 5 June 2019

Published online: 12 June 2019

\section{References}

1. Cassinello F, Prieto I, del OM, Rivas S, Strichartz GR. Cancer surgery: how may anesthesia influence outcome. J Clin Anesth. 2015;27(3):262-72.

2. Shakhar G, Ben-Eliyahu S. Potential prophylactic measures against postoperative immunosuppression: could they reduce recurrence rates in oncological patients. Ann Surg Oncol. 2003;10(8):972-92.

3. Xu YJ, Li SY, Cheng Q, et al. Effects of anaesthesia on proliferation, invasion and apoptosis of LoVo colon cancer cells in vitro. Anaesthesia. 2016;71(2):147-54

4. O'Dwyer MJ, Owen HC, Torrance HD. The perioperative immune response. Curr Opin Crit Care. 2015;21(4):336-42.

5. Luo JL, Maeda S, Hsu LC, Yagita H, Karin M. Inhibition of NF-kappaB in cancer cells converts inflammation- induced tumor growth mediated by TNFalpha to TRAIL-mediated tumor regression. Cancer Cell. 2004;6(3):297-305.

6. Tan W, Zhang W, Strasner A, et al. Tumour-infiltrating regulatory $T$ cells stimulate mammary cancer metastasis through RANKL-RANK signalling. Nature. 2011:470(7335):548-53.

7. Hou M, Zhou NB, Li H, et al. Morphine and ketamine inhibit immune function of gastric cancer patients by increasing percentage of CD4(+ )CD25(+)Foxp3(+) regulatory T cells in vitro. J Surg Res. 2016;203(2):306-12.

8. Oka M, Hazama S, Suzuki M, et al. Depression of cytotoxicity of nonparenchymal cells in the liver after surgery. Surgery. 1994;116(5):877-82.

9. Müller-Edenborn B, Frick R, Piegeler T, et al. Volatile anaesthetics reduce neutrophil inflammatory response by interfering with $C X C$ receptor-2 signalling. Br J Anaesth. 2015;114(1):143-9.

10. Wigmore TJ, Mohammed K, Jhanji S. Long-term survival for patients undergoing volatile versus IV anesthesia for Cancer surgery: a retrospective analysis. Anesthesiology. 2016;124(1):69-79.

11. Cata JP, Chavez-MacGregor M, Valero V, et al. The impact of paravertebral block analgesia on breast Cancer survival after surgery. Reg Anesth Pain Med. 2016:41(6):696-703.

12. Yi W, Li D, Guo Y, Zhang Y, Huang B, Li X. Sevoflurane inhibits the migration and invasion of glioma cells by upregulating microRNA-637. Int J Mol Med. 2016;38(6):1857-63.

13. Connolly C, Buggy DJ. Opioids and tumour metastasis: does the choice of the anesthetic-analgesic technique influence outcome after cancer surgery. Curr Opin Anaesthesiol. 2016;29(4):468-74.

14. Kim R. Anesthetic technique and cancer recurrence in oncologic surgery: unraveling the puzzle. Cancer Metastasis Rev. 2016.

15. Hiller JG, Hacking MB, Link EK, Wessels KL, Riedel BJ. Perioperative epidural analgesia reduces cancer recurrence after gastro-oesophageal surgery. Acta Anaesthesiol Scand. 2014;58(3):281-90.

16. Cummings KC, Patel M, Htoo PT, Bakaki PM, Cummings LC, Koroukian S. A comparison of the effects of epidural analgesia versus traditional pain management on outcomes after gastric cancer resection: a populationbased study. Reg Anesth Pain Med. 2014:39(3):200-7.

17. Pérez-González O, Cuéllar-Guzmán LF, Navarrete-Pacheco M, Ortiz-Martínez JJ, Williams WH, Cata JP. Impact of regional anesthesia on gastroesophageal Cancer surgery outcomes: a systematic review of the literature. Anesth Analg. 2018;127(3):753-8.

18. Ben-David B. Anaesthesia in Cancer surgery: can it affect Cancer survival. Curr Clin Pharmacol. 2016;11(1):4-20.

19. Byrne K, Levins KJ, Buggy DJ. Can anesthetic-analgesic technique during primary cancer surgery affect recurrence or metastasis. Can J Anaesth. 2016; 63(2):184-92.

20. Jones SA, Jenkins BJ. Recent insights into targeting the IL-6 cytokine family in inflammatory diseases and cancer. Nat Rev Immunol. 2018;18(12):773-89.

21. Cui M, Gong C, Jiang B, et al. Evaluation of immune responses of gastric cancer patients treated by laparoscopic and open gastrectomy. Med Oncol. 2015, 32(11):253

22. Yanagimoto $Y$, Takiguchi S, Miyazaki Y, et al. Comparison of pain management after laparoscopic distal gastrectomy with and without epidural analgesia. Surg Today. 2016;46(2):229-34.

23. Salicath $\mathrm{JH}$, Yeoh EC, Bennett MH. Epidural analgesia versus patientcontrolled intravenous analgesia for pain following intra-abdominal surgery in adults. Cochrane Database Syst Rev. 2018;(8):CD010434.

24. Wang L, Li X, Chen H, Liang J, Wang Y. Effect of patient-controlled epidural analgesia versus patient-controlled intravenous analgesia on postoperative pain management and short-term outcomes after gastric cancer resection: a retrospective analysis of 3,042 consecutive patients between 2010 and 2015. J Pain Res. 2018:11:1743-9.

25. Hole A, Terjesen T, Breivik H. Epidural versus general anaesthesia for total hip arthroplasty in elderly patients. Acta Anaesthesiol Scand. 1980;24(4):27987.

26. Rem J, Brandt MR, Kehlet H. Prevention of postoperative lymphopenia and granulocytosis by epidural analgesia. Lancet. 1980;1(8163):283-4.

27. Neeman E, Ben-Eliyahu S. Surgery and stress promote cancer metastasis: new outlooks on perioperative mediating mechanisms and immune involvement. Brain Behav Immun. 2013, 30 Suppl:S32-40.

28. Ahlers $\mathrm{O}$, Nachtigall I, Lenze J, et al. Intraoperative thoracic epidural anaesthesia attenuates stress-induced immunosuppression in patients undergoing major abdominal surgery. Br J Anaesth. 2008;101(6):781-7.

29. Melamed R, Rosenne E, Shakhar K, Schwartz Y, Abudarham N, Ben-Eliyahu S. Marginating pulmonary-NK activity and resistance to experimental tumor metastasis: suppression by surgery and the prophylactic use of a betaadrenergic antagonist and a prostaglandin synthesis inhibitor. Brain Behav Immun. 2005;19(2):114-26.

30. Sekandarzad MW, van Zundert AA, Lirk PB, Doornebal CW, Hollmann MW. Perioperative anesthesia care and tumor progression. Anesth Analg. 2016.

31. Buckley A, McQuaid S, Johnson P, Buggy DJ. Effect of anaesthetic technique on the natural killer cell anti-tumour activity of serum from women undergoing breast cancer surgery: a pilot study. Br J Anaesth. 2014, 113(Suppl 1):i56-62.

32. Xu YJ, Chen WK, Zhu Y, Wang SL, Miao CH. Effect of thoracic epidural anaesthesia on serum vascular endothelial growth factor $\mathrm{C}$ and cytokines in patients undergoing anaesthesia and surgery for colon cancer. $\mathrm{Br} J$ Anaesth. 2014, 113(Suppl 1):i49-55.

33. Gasparini G, Longo R, Sarmiento R, Morabito A. Inhibitors of cyclo-oxygenase 2 : a new class of anticancer agents. Lancet Oncol. 2003;4(10):605-15.

34. Hosokawa T. Effect of anesthesia and surgery on cell-mediated immunity-the application of two color analysis to classification of functional lymphocyte subpopulation. Masui. 1987:36(6):956-61.

35. Hosokawa T, Hori Y, Ohtsuka T, Nakagawa H, Miyazaki M. Effect of anesthesia and surgery on immunity in patients with benign and malignant diseases. Masui. 1989;38(3):343-9.

36. Hashimoto T, Hashimoto S, Hori Y, Nakagawa H, Hosokawa T. Epidural anaesthesia blocks changes in peripheral lymphocytes subpopulation during gastrectomy for stomach cancer. Acta Anaesthesiol Scand. 1995;39(3):294-8.

37. Hole A, Unsgaard G. The effect of epidural and general anaesthesia on lymphocyte functions during and after major orthopaedic surgery. Acta Anaesthesiol Scand. 1983:27(2):135-41.

38. Page GG, Blakely WP, Ben-Eliyahu S. Evidence that postoperative pain is a mediator of the tumor-promoting effects of surgery in rats. Pain. 2001;90(1-2):191-9.

39. Greenfeld K, Avraham R, Benish M, et al. Immune suppression while awaiting surgery and following it: dissociations between plasma cytokine levels, their induced production, and NK cell cytotoxicity. Brain Behav Immun. 2007:21(4):503-13.

40. Goldfarb Y, Ben-Eliyahu S. Surgery as a risk factor for breast cancer recurrence and metastasis: mediating mechanisms and clinical prophylactic approaches. Breast Dis. 2006;26:99-114

41. Sasada T, Kimura M, Yoshida Y, Kanai M, Takabayashi A. CD4+CD25+ regulatory T cells in patients with gastrointestinal malignancies: possible involvement of regulatory T cells in disease progression. Cancer. 2003;98(5):1089-99.

42. Liu S, Carpenter RL, Neal JM. Epidural anesthesia and analgesia. Their role in postoperative outcome. Anesthesiology. 1995;82(6):1474-506.

\section{Publisher's Note}

Springer Nature remains neutral with regard to jurisdictional claims in published maps and institutional affiliations. 